\title{
SCREENING OF FUNGAL STRAINS FOR REMEDIATION OF WATER AND SOIL CONTAMINATED WITH SYNTHETIC DYES
}

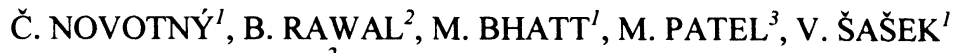 \\ and H. P. MOLITORIS ${ }^{2}$ \\ ${ }^{1}$ Institute of Microbiology, Academy of Sciences of the Czech Republic, \\ Videňská 1083, 14220 Prague 4, Czech Republic; ${ }^{2}$ Botanical Institute, \\ University of Regensburg, Universitätsstrasse 31, D-93040 Regensburg, \\ Germany; ${ }^{3}$ Department of Biosciences, S.P. University, Vidyanagar- \\ 388120, India
}

\begin{abstract}
Using Remazol Brilliant Blue R (RBBR), strains of terrestrial white rot (WRF) and marine fungi (MF) were screened for efficient decolorization. Dye degradation potential of selected strains was studied with chemically different dyes (azo, anthraquinone, heterocyclic, triphenylmethane). Irpex lacteus and Pleurotus ostreatus (WRF) efficiently degraded dyes from all groups whereas less efficient and selective degradations were observed with Dactylospora haliotrepha and Aspergillus ustus (MF). Seawater salinity often reduced decolorization efficiency of WRF but increased decolorization ability of MF. In soil I. lacteus removed $77 \%$ of RBBR used at 150 $\mu \mathrm{g} / \mathrm{g}$ within 6 weeks. The work presents fungi as suitable candidates to be applied to re-mediation of dye-contaminated water and soil.
\end{abstract}

\section{Introduction}

More than 10000 commercially available dyes representing a total of 700000 tons of dyestuff are produced worldwide annually, $10 \%$ of which enters industrial effluents. Many dyes are resistant to conventional wastewater treatment (Shaul et al. 1991) and, therefore, the need exists for development of new processes for treating those effluents. Bioremediation by fungi offers an alternative since some ligninolytic species are efficient dye degraders (Paszczynski and Crawford 1995; Banat et al. 1996; etc.).

The biodegradation potential of the majority of ligninolytic fungal species existing in nature as well as of marine fungal species is poorly known (Paszczynski and Crawford 1995; Raghukumar et al. 1996; Swamy and Ramsay 1999). The purpose of our study was to select strains of terrestrial white rot and marine fungi that would effectively decolorize recalcitrant dyes and would be applicable to bioremediation of dye-contaminated water and soil. Since in some countries the pollution with dyes affects large areas of marine coast environment, the effect of seawater salinity on decolor-ization capacities of the selected fungal strains was documented. 


\section{Material and Methods}

\subsection{MICROORGANISMS}

The following strains of terrestrial fungi were used: Bjerkandera adusta 606/93; Ceriporia metamorphosa 193/93; Daedaleopsis confragosa 491/93; Ganoderma lucidum 530/93; Irpex lacteus 617/93; Mycoacia sp. 446/93; Pachykytospora tuberculosa 505/93; Phellinus pseudopunctatus 538/93; Phellinus punctatus 421/93; Pleurotus ostreatus 670/93; Stereum rugosum 210/93; Trametes versicolor 167/93 and Tyromyces chioneus 616/93.

The following marine micromycetes were used: Anguillospora longissima M234; Aniptodera mangrovei M235; Aspergillus ustus M224; Banhegia setispora M236; Bathyascus sp. M237; Corollospora pulchella M217; Dactylospora haliotrepha M240; Flagellospora curvula M241; Hypoxylon oceanicum M244; Lulworthia grandispora M245; Paraliomyces lentiferus M248; and Zalerion sp. M249.

All strains were maintained on MEG agar slants at $4{ }^{\circ} \mathrm{C}$.

\subsection{SCREENING ON AGAR PLATES AND BIODEGRADATION OF DYES}

The following agar (20 g/L; Oxoid, U.K.) media were used, containing (per liter): MEG $\mathrm{pH} 4.5,5 \mathrm{~g}$ malt extract and $10 \mathrm{~g}$ glucose; YEPG $\mathrm{pH} 4.5,2 \mathrm{~g}$ yeast extract, $5 \mathrm{~g}$ peptone, $10 \mathrm{~g}$ glucose, $1 \mathrm{~g} \mathrm{KH}_{2} \mathrm{PO}_{4}$ and $0.5 \mathrm{~g} \mathrm{MgSO}_{4} .7 \mathrm{H}_{2} \mathrm{O}$; low nitrogen mineral medium (Tien and Kirk 1988) $\mathrm{pH} 4.5$ (LNMM); and GPY pH 6.0, $1 \mathrm{~g}$ glucose, $0.5 \mathrm{~g}$ peptone and 0.1 yeast extract. Artificial seawater ( $3 \%$ salinity, W/V) was according to Lorenz and Molitoris (1997). Sterilization was done by autoclaving $\left(120^{\circ} \mathrm{C}, 20 \mathrm{~min}\right)$.

Decolorization of dyes was evaluated after inoculation of the dye-containing (200 $\mu \mathrm{g} / \mathrm{mL}$ ) agar plate with a mycelium-covered disc removed from a fresh MEG culture and subsequent incubation at the appropriate temperature. Decolorization and growth were read in time. Control plates without fungal inoculation were always included in the experiments. All cultures were run in duplicate.

The following dyes were used: Methyl Red (monoazo; Sigma, Germany), Methyl Orange (monoazo; Lachema, Czech Republic), Reactive Orange 16 (monoazo; Aldrich, USA), Congo Red (disazo; Merck, Germany), Reactive Black 5 (disazo; Aldrich, Germany), Naphthol Blue Black (disazo; Aldrich, USA), Remazol Brilliant Blue R (RBBR) (anthraquinone; Sigma, USA), Disperse Blue 3 (anthraquinone; Aldrich, USA), Fluorescein (heterocyclic; Lachema, Czech Republic), Methylene Blue (heterocyclic thiazine; Merck, Germany), Bromophenol Blue (triphenylmethane; Lachema, Czech Republic).

\subsection{SCREENING WITH RBBR-CELLULOSE}

Two-layer agar medium based on artificial seawater (Lorenz and Molitoris 1997) containing (per liter) $0.5 \mathrm{~g}$ peptone, $0.1 \mathrm{~g}$ yeast extract and $16 \mathrm{~g}$ agar was used, the upper 
layer contained $5 \mathrm{~g}$ RBBR-cellulose per liter. The medium was inoculated on the top with a mycelium-covered disc removed from a fresh fungal culture and incubated at for 7 weeks to detect cellulase activity and decolorization of RBBR.

\subsection{DYE DEGRADATION IN SOIL}

An amount of $8 \mathrm{~g}$ of dry tyndalized brown soil (particles $<2 \mathrm{~mm}$; native humidity 5.4 $\%$, $\mathrm{pH} 6.5$, organic carbon $4.7 \%$ glucose equivalent) was used in $100-\mathrm{mL}$ Erlenmeyer flasks. The soil was homogenously spiked with RBBR (final concentration $150 \mu \mathrm{g} / \mathrm{g}$; moisture content $20 \%, \mathrm{~W} / \mathrm{W})$. Freshly prepared, straw-grown 1 . lacteus $(8.0 \mathrm{~g})$ was mixed with the RBBR-spiked soil. Controls contained either heat-killed inoculum or sterilized straw without the fungus. All flasks were incubated at $28^{\circ} \mathrm{C}$. The contaminated soil was extracted and analyzed on days $0,14,28,35,42$ and 49 after inoculation. All live samples and controls were extracted and analyzed in triplicate.

RBBR was extracted from the spiked soil using a multisolvent system made up of chloroform, methanol and distilled water $(1: 1: 1, \mathrm{~V} / \mathrm{V})$. Each solvent was added separately in the above order, followed by mixing and vigorous shaking of the soil sample. The soil sample was sonicated $(15 \mathrm{~min})$ and filtered, the filtrate was collected and chloroform removed using a separation funnel. After centrifugation the filtrate was placed in an open glass Petri dish and the solvents evaporated at $100^{\circ} \mathrm{C}$ for $6-8 \mathrm{~h}$. The residues were redissolved in distilled water and centrifuged. After dilution, absorbance was read at $578 \mathrm{~nm}$ using a Perkin-Elmer $\lambda 11$ UV-VIS spectrophotometer.

\section{Results and Discussion}

\subsection{SCREENING OF TERRESTRIAL AND MARINE FUNGI}

A broader preselection (not shown) using RBBR of terrestrial, wood-rotting fungal strains capable of efficient decolorization of dyes involved more than 100 strains collected in forests of central Europe or obtained from the Culture Collection of Basidiomycetes, Institute of Microbiology, Prague, to cover the following genera: Abortiporus, Agaricus, Anthrodia, Aspergillus, Aurantioporus, Aureobasidium, Bjerkandera, Ceriporia, Cerrena, Coriolopsis, Daedalea, Daedaleopsis, Dictyostelium. Flammulina, Fomes, Fomitopsis, Ganoderma, Gleophyllum, Grifola, Hapalopilus, $\mathrm{Hy}$ menochaete, Inonotus, Irpex, Ischnoderma, Laricifomes, Lentinus, Leucoagaricus, Mycoacia, Pachykytospora, Panus, Phaeolus, Phallus, Phanerochaete, Phellinus, Phlebia, Phlebiopsis, Phlyctochytrium, Pycnoporus, Pilatoporus, Pleurotus, Podospora, Schizophyllum, Sphaerobolus, Spongipellis, Stereum, Trametes, Tyromyces.

Table 1 documents that the most efficient of the preselected RBBR degraders were able to grow well in the presence of the dye and decolorized the plate completely within 10 days. The decolorization efficiency was tested in mineral and complex media conditions. The content of nitrogen source, known to control the production of ligninolytic peroxidases in white rot fungi (Kaal et al. 1995), was from $0.002-0.003 \%$ (LNMM, MEG) to $0.07 \%$ (YEPG). Some strains decolorized RBBR rapidly under 
broad nutritive conditions (I. lacteus, $T$. versicolor) others preferred specific conditions to a different degree (C. metamorphosa, B. adusta, $P$. ostreatus) (Table 1).

I. lacteus and $P$. ostreatus efficiently colonized sterile soil by exploratory mycelium whereas $T$. versicolor was capable of only a partial colonization and $B$. adusta did not grow into the soil at all (not shown). Therefore, I. lacteus and $P$. ostreatus were chosen for the comparison of their decolorizing capacities with those of marine fungi.

Screening of dye-degrading strains of marine fungi originating from the Botanical Institute, University of Regensburg with RBBR-cellulose was carried out under the conditions of both freshwater and seawater salinity (not shown). Only two of the fungi, $A$. ustus and $D$. haliotrepha, were able to decolorize the plates at both salinities and were therefore used in the comparative study.

TABLE 1. Screening of wood-rotting fungal strains on RBBR-containing agar media.

\begin{tabular}{|c|c|c|c|c|c|c|}
\hline \multirow[t]{3}{*}{ Fungus } & \multicolumn{6}{|c|}{ Medium ${ }^{1,2}$} \\
\hline & \multicolumn{2}{|c|}{ YEPG } & \multicolumn{2}{|c|}{ MEG } & \multicolumn{2}{|c|}{ LNMM } \\
\hline & $\mathrm{A}^{3}$ & $\mathrm{~B}^{4}$ & $\mathrm{~A}^{3}$ & $\mathrm{~B}^{4}$ & $\mathrm{~A}^{3}$ & $\mathrm{~B}^{4}$ \\
\hline Bjerkandera adusta & 7 & 9 & 10 & 9 & $\mathrm{P}$ & 17 \\
\hline Cerioporia metamorphosa & 6 & - & 7 & 7 & 7 & 7 \\
\hline Daedaleopsis confragosa & $\mathrm{P}$ & 21 & $\mathbf{P}$ & - & $\mathbf{P}$ & - \\
\hline Ganoderma lucidum & $\mathbf{P}$ & 21 & 12 & 14 & 12 & 17 \\
\hline Irpex lacteus & 5 & 9 & 7 & 7 & 9 & 7 \\
\hline Mycoacia sp. & 14 & 14 & 14 & 14 & 14 & 14 \\
\hline Pachykytospora tuberculosa & $P$ & - & $P$ & - & $P$ & $\mathbf{P}$ \\
\hline Phellinus pseudopunctatus & 19 & 19 & 17 & 14 & 14 & 14 \\
\hline Phellinus punctatus & 17 & 17 & 17 & 16 & $\mathrm{P}$ & 17 \\
\hline Pleurotus ostreatus & 10 & 10 & 10 & 9 & 14 & 20 \\
\hline Stereum rugosum & 17 & - & 17 & 16 & $\mathbf{P}$ & 20 \\
\hline Trametes versicolor & 9 & 10 & 7 & 7 & $\mathrm{P}$ & 10 \\
\hline Tyromyces chioneus & $\mathbf{P}$ & 27 & 10 & 10 & 14 & 14 \\
\hline
\end{tabular}

${ }^{1}$ Culture medium contained $200 \mathrm{mg}$ RBBR per litre; ${ }^{2}$ cultures were incubated at $28^{\circ} \mathrm{C}$

for 27 days;

${ }^{3}$ A - growth expressed as a number of days necessary for colonization of the whole plate; $\mathrm{P}$, only a part of the plate surface was colonized within 27 days; ${ }^{4} \mathrm{~B}$ decolorization expressed as a number of days necessary for complete decolorization of the plate; P, partial decolorization after 27 weeks; - , no decolorization.

\subsection{DECOLORIZATION OF VARIOUS DYES}

In order to compare dye degradation capacities of the selected representatives of terrestrial ligninolytic basidiomycetes and marine micromycetes, a set of compounds belonging to four major groups of recalcitrant dyes was used (Table 2). Terrestrial fungi were superior to marine fungi in having the ability to decolorize all types of dyes. I. lacteus and $P$. ostreatus thus belong to those few white rot fungal species, such as $T$. versicolor, $P$. chrysosporium and Bjerkandera sp., that are capable of efficient decolorization of a broad spectrum of chemically different dyes (Knapp et al. 1995; Swamy and Ramsay 1999). The results obtained with $P$. ostreatus (Table 2) confirmed those of Knapp et al. (1995) who demonstrated the ability of their natural isolate of this fungal species to decolorize high concentrations of various azo-, anthraquinone-, Cuphthalocyanine- and triphenylmethane dyes. $D$. haliotrepha was able to attack all dyes except for Reactive Orange 16 and Disperse Blue 3, but many dyes were decolorized 
only partially. A. ustus was able to attack only less than a half of the dyes tested and the decolorization was mostly incomplete (Table 2). We cannot compare our data obtained with the two latter fungi with those of other studies since the ability of marine fungi to degrade synthetic dyes is mostly unknown (Raghukumar et al. 1996).

Decolorization by terrestrial fungi of some dyes was slowed down or even completely blocked by seawater salinity (Table 2). In some cases, however, the decolorization was not affected by the salinity or even a positive effect could be observed (Congo Red). Different effects of the salinity in I. lacteus and P. ostreatus were observed in the case of degradation of Disperse Blue 3, Fluorescein and Bromophenol Blue (Table 2). Reasons for such diverse salinity effects on decolorization of various dyes by white-rot fungi are unknown.

As far as the marine fungi were concerned, seawater salinity enabled them to degrade disazo-, anthraquinone-, heterocyclic- and triphenylmethane dyes (Table 2). On the other hand, Methyl Red and, in the case of D. haliotrepha, also Congo Red, could be decolorized only if deionized water was used to prepare the medium.

In general, the results confirm the hypothesis of a lower degree of salinity stress (cf. Capone and Bauer 1992) in the marine fungi compared to the terrestrial ones. However, the decolorization by $I$. lacteus and $P$. ostreatus under seawater salinity conditions shows that even under those stressing conditions these fungi can use their biochemical machinery for dye degradation.

\subsection{DYE DEGRADATION IN SOIL}

The ability of $I$. lacteus to degrade dyes in soil was tested using RBBR at $150 \mu \mathrm{g} / \mathrm{g}$

TABLE 2. Decolorization of synthetic dyes by terrestrial and marine fungi on agar medium containing deionized water or articifial seawater

\begin{tabular}{|c|c|c|c|c|c|c|c|c|}
\hline \multirow[t]{3}{*}{ Dye } & \multicolumn{8}{|c|}{ Decolorization efficiency } \\
\hline & \multicolumn{2}{|c|}{ Irpex lacteus } & \multicolumn{2}{|c|}{ Pleurotus ostreatus } & \multicolumn{2}{|c|}{ Dactylospora hal. } & \multicolumn{2}{|c|}{ Aspergillus ustus } \\
\hline & $\mathrm{DW}^{2}$ & $\mathrm{SW}^{3}$ & $\mathrm{DW}^{2}$ & $S W^{3}$ & $\mathrm{DW}^{2}$ & $\mathrm{SW}^{3}$ & $\mathrm{DW}^{2}$ & SW \\
\hline Methyl Red & 9 & 29 & 15 & $\mathbf{P}$ & 10 & - & 17 & - \\
\hline Methyl Orange & 9 & 11 & 10 & 25 & 12 & P & - & - \\
\hline Reactive Orange 16 & 10 & 14 & 15 & 29 & - & - & - & - \\
\hline Congo Red & 20 & 14 & 22 & 14 & $\mathbf{p}$ & - & - & - \\
\hline Reactive Black 5 & 11 & 16 & 13 & 14 & - & 25 & - & $\mathbf{P}$ \\
\hline Naphtol Blue Black & 27 & 25 & 17 & 16 & - & 38 & - & $\mathbf{P}$ \\
\hline RBBR & 10 & 10 & 13 & 14 & - & $\mathbf{P}$ & - & $\mathbf{P}$ \\
\hline Disperse Blue 3 & 17 & 16 & 12 & 38 & - & - & - & $\mathbf{P}$ \\
\hline Fluorescein & 15 & 11 & 13 & 21 & - & P & - & - \\
\hline Methylene Blue & 22 & 25 & 20 & - & - & $P$ & - & - \\
\hline Bromophenol Blue & 12 & 12 & 27 & 14 & - & $\mathbf{P}$ & - & - \\
\hline
\end{tabular}

${ }^{1}$ Cultures were incubated at $22^{\circ} \mathrm{C}$ for 6 weeks. Decolorization is expressed as a number of days necessary for complete decolorization of the plate; $P$, partial decolorization after 6 weeks; - , no decolorization; ${ }^{2} \mathrm{DW}, \mathrm{GPY}$ medium based on deionized water, ' $S W$.

GPY medium based on artificial seawater

as the model dye. The tyndalized, RBBR-spiked soil was inoculated by mixing with freshly prepared, straw-grown fungal inoculum and the dye removal was detected in time. After 6 weeks, $77 \%$ of the original amount of RBBR was removed, the 
disappearance being linear at a constant rate of $2.8 \mu \mathrm{g} R B B R / g$ soil per day (not shown). The results suggest that recalcitrant dyes, like other organopollutants, can be removed from the soil environment by the action of ligninolytic fungi (cf. Andersson and Henrysson 1996; Novotný et al. 1999; etc.).

The study demonstrates that effective dye degraders applicable to remediation of freshwater, seawater and soil environments contaminated with recalcitrant dyes can be screened from among unknown strains of terrestrial and marine fungal organisms.

\section{Acknowledgements}

The work was supported by the Czech-German project WTZ-TSR-040-97 and by grants of the Grant Agency of the Czech Republic No. 526/99/0519 and 526/00/1303. The authors thank P. Vampola for providing the strains of basidiomycete fungi. Part of the results was presented at the Symposium on Biotechnology in the Textile Industry, May 3-7, 2000, Portugal.

\section{References}

1. Andersson, B.E. and Henrysson, T. (1996) Accumulation and degradation of dead-end metabolites during treatment of soil contaminated with polycyclic aromatic hydrocarbons with five strains of white-rot fungi, Appl Microbiol. Biotechnol. 46, 647-652.

2. Banat, I.M., Nigam, P., Singh, D. and Marchant, R. (1996) Microbial decolorization of textile-dyecontaining effluents: a review, Bioresource Technol. 58, 217-227.

3. Capone, D.G. and Bauer, J.E. (1992) Microbial processes in coastal pollution, in R. Mitchell (ed.), Environmental Microbiology, Wiley-Liss, New York, pp. 191-237.

4. Kaal, E.J., Field, J.A., Joyce, T.W. (1995) Increasing ligninolytic enzyme activities in several white rot basidiomycetes by nitrogen-sufficient media, Bioresource Technol. 53, 133-139.

5. Knapp, J.S., Newby, P.S. and Reece, L.P. (1995) Decolorization of dyes by wood-rotting basidiomycete fungi, Enzyme Microb. Technol. 17, 664-668

6. Lorenz, R. and Molitoris, H.P. (1997) Cultivation of fungi under simulated deep sea conditions, Mycol. Res. 101, 1355-1365.

7. Novotný, Č., Erbanová, P., Sašek, V., Kubátová, A., Cajthaml, T., Lang, E., Krahl, J. and Zadražil, F. (1999) Extracellular oxidative enzyme production and PAH removal in soil by exploratory mycelium of white rot fungi, Biodegradation 10, 159-168.

8. Paszczynski, A. and Crawford, R.L. (1995) Potential for bioremediation of xenobiotic compounds by the white rot fungus Phanerochaete chrysosporium, Biotechnol. Progr. 11, 368-379.

9. Raghukumar, C., Chandramohan, D., Michel, F.C. and Reddy, C.A. (1996) Degradation of lignin and decolorization of paper mill bleach plant effluent (BPE) by marine fungi, Biotechnol. Lett. 18, 105 106.

10. Shaul, G.M., Holdsworth, T.J., Dempsey, C.R. and Dostall, K.A. (1991) Fate of water soluble azo dyes in the activated sludge process, Chemosphere 22, 107-119.

11. Swamy, J. and Ramsay, J.A. (1999) The evaluation of white rot fungi in the decoloration of textile dyes, Enzyme Microbial. Technol. 24, 130-137.

12. Tien, M. and Kirk, T.K. (1988) Lignin peroxidase of Phanerochaete chrysosporium, Methods Enzymol. 161, 238-249. 